\title{
Gravity Load Collapse Behavior of Nonengineered Reinforced Concrete Columns
}

\author{
Chichaya Boonmee $\left(\mathbb{D},{ }^{1}\right.$ Kittipoom Rodsin $\left(\mathbb{D},{ }^{2}\right.$ and Krissachai Sriboonma ${ }^{1}$ \\ ${ }^{1}$ Department of Teacher Training in Civil Engineering, Faculty of Technical Education, \\ King Mongkut's University of Technology North Bangkok, Bangkok, Thailand \\ ${ }^{2}$ Department of Civil and Environmental Engineering Technology, \\ Center of Excellence in Structural Dynamics and Urban Management, The College of Industrial Technology, \\ King Mongkut's University of Technology North Bangkok, Bangkok, Thailand
}

Correspondence should be addressed to Kittipoom Rodsin; kittipoom.kmutnb@gmail.com

Received 27 October 2017; Accepted 28 December 2017; Published 18 March 2018

Academic Editor: Peng Zhang

Copyright ( $) 2018$ Chichaya Boonmee et al. This is an open access article distributed under the Creative Commons Attribution License, which permits unrestricted use, distribution, and reproduction in any medium, provided the original work is properly cited.

\begin{abstract}
This paper aims at investigating gravity load collapse behavior of extremely poor quality reinforced concrete columns under cyclic loading. Such columns were usually constructed by local people and may not be designed to meet any of the standards. It was found that their concrete strength may be as low as $5 \mathrm{MPa}$ and the amount of longitudinal reinforcement may be lower than $1 \%$. This type of column is deliberately defined as "nonengineered reinforced concrete column," or NRCC. During earthquake, the gravity load collapse of the NRCC columns caused a large number of death tolls around the world. In this study, four columns as representative of existing NRCC were tested under cyclic loading. The compressive strength of concrete in order of $5 \mathrm{MPa}$ was used to be representative of columns with poor quality concrete. Two axial load levels of 6 and 18 tons were used to study the influence of axial load level on maximum drift at gravity load collapse. To investigate the effect of bar types on drift capacity, $9 \mathrm{~mm}$ round bars were used in two specimens and $12 \mathrm{~mm}$ deformed bars were used for the rest of the specimens. The maximum drift before gravity load collapse was very dependent on the axial load level. The maximum drift of the specimens subjected to high axial load (18 tons) was extremely low at approximately $1.75 \%$ drifts. The use of deformed bars (associated with larger amount of longitudinal reinforcement) caused the damage to severely dissipate all over the height of the columns. Such damage caused columns to collapse at a lower drift compared to those using round bars. Finally, the plastic hinge model was used to predict the maximum drift of the low strength columns. It was found that the model overly underestimates the drift at gravity load collapse.
\end{abstract}

\section{Introduction}

During several past decades, earthquake engineering research has been undertaken to better understanding structural behavior under severe earthquake. To prevent structural damage or collapse under strong seismic excitation, the structural design using ductile detailing of RC structures has been investigated [1-5]. For existing or old building, many strengthening approaches such as wrapping structures using carbon fiber reinforced polymer (CFRP) [6-11], steel jacketing, and buckling restrained bracing (BRB) have been developed [12-15]. Most design methods and strengthening techniques developed in the past decades were found to be very effective and experimentally proved to be able to prevent the building collapse from strong earthquake [16]. If the findings from earthquake research and development could be practically applied, the number of death tolls from earthquake around the world should be significantly reduced. However, during the recent earthquake such as Sichuan earthquake in 2008 [17] and Haiti earthquake in 2010, the total number of death toll was more than 200,000 [18]. The collapse of buildings is shown in Figure 1.

A large number of death from earthquake implied that the current earthquake engineering knowledge is not effectively applicable for the structures in these regions [19]. 


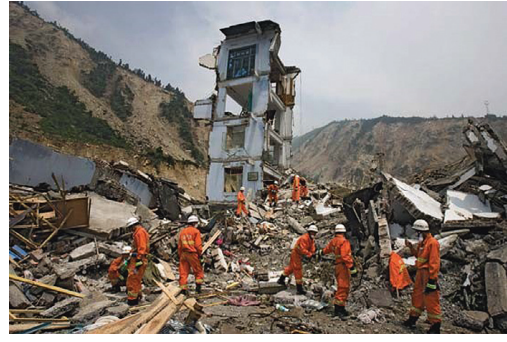

(a)

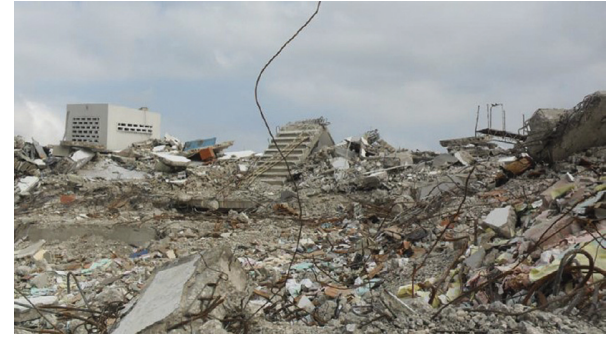

(b)

Figure 1: (a) Rescue workers searching for survivors after a major earthquake struck Sichuan [17]. (b) Complete destruction of concrete building in Haiti (photo: R. DesRoches) [18].

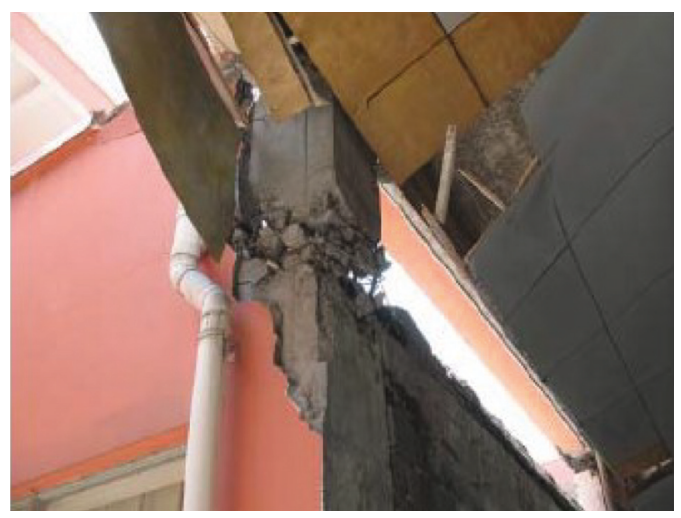

(a)

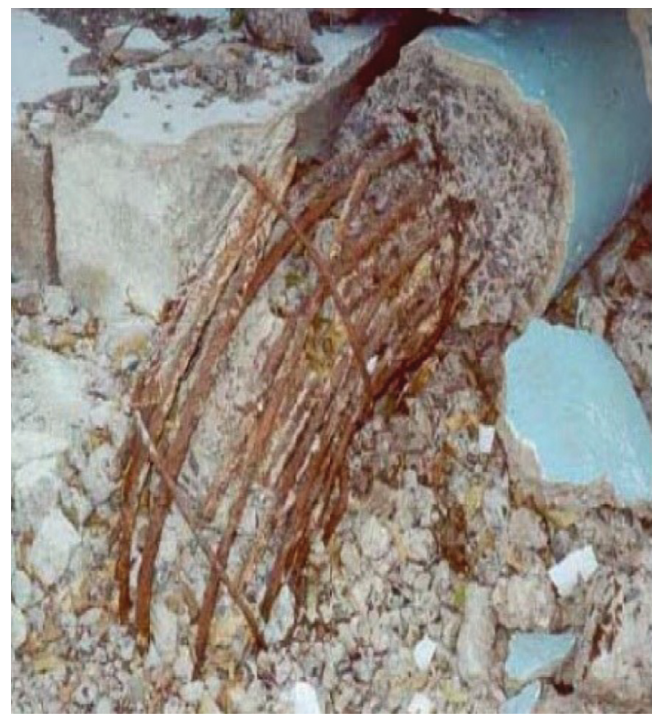

(c)

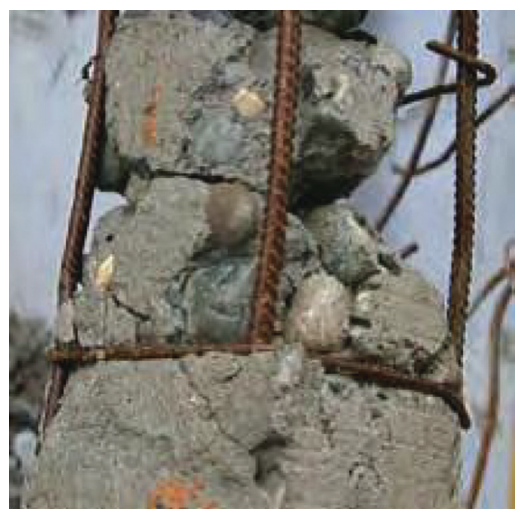

(b)

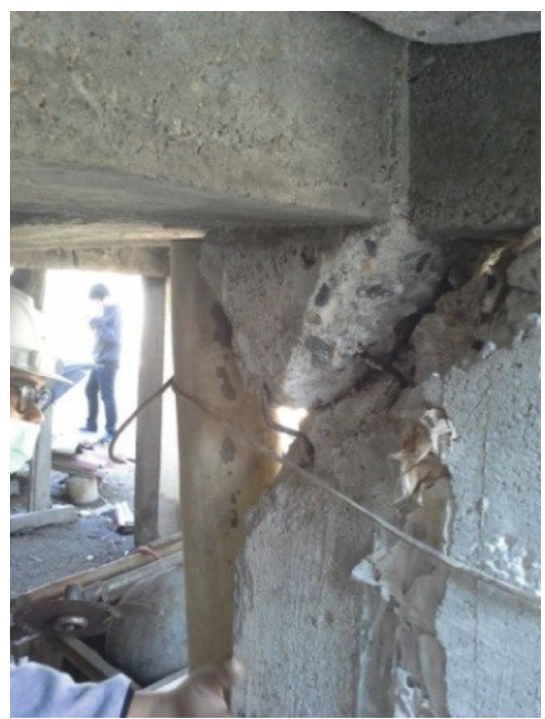

(d)

Figure 2: (a) Poor reinforcement detailing in Sichuan [20]. (b) Poor quality concrete in Sichuan [21]. (c) Collapsed column with inadequate lap splice length and widely spaced transverse bars in Gujarat, India [22]. (d) Poor reinforcement detailing in Chiang Rai [23].

The structures in these regions were found to be poorly constructed and not conformed to any design standard as shown in Figure 2. The structure constructed by local people using material or reinforcement detailed below the design standard may be classified as "nonengineered structures." In this study, the columns are of most interest. This type of column is defined as "nonengineered reinforced concrete column," or NRCC. These structures are very vulnerable to the earthquake. Significantly, there are very limited numbers of research on seismic behavior of such structures under the earthquake. The construction cost of these structures is extremely low, and hence any available strengthening methods are considered too expensive to be practically used for retrofitting these structures. 
TABle 1: Summaries of mix properties for concrete.

\begin{tabular}{lccccc}
\hline Mix type & Design strength $(\mathrm{MPa})$ & Cement $\left(\mathrm{kg} / \mathrm{m}^{3}\right)$ & Water $\left(\mathrm{kg} / \mathrm{m}^{3}\right)$ & Sand $\left(\mathrm{kg} / \mathrm{m}^{3}\right)$ & Aggregate $\left(\mathrm{kg} / \mathrm{m}^{3}\right)$ \\
\hline All column & 5.0 & 160 & 200 & 1000 & 937 \\
\hline
\end{tabular}

To economically and effectively retrofit these structures, the behavior of the structures under earthquake should be studied prior to develop a proper strengthening approach [24]. Therefore, in this study, the behavior of four column specimens as representative of nonengineered columns, or NRCC, was tested to investigate their seismic behavior. The gravity load-carrying mechanism and collapse behavior are of most interest. The test setup and test results will be discussed in the next sections.

\section{Experimental Program}

2.1. Test Specimen. Four column specimens (12L-0.2, 12L$0.6,9 \mathrm{~L}-0.2$, and 9L-0.6) as representative of prototype columns with low strength concrete in order of $5 \mathrm{MPa}$ were tested under cyclic loading. It is noted that to control mix proportion of low concrete strength to be exactly $5 \mathrm{MPa}$ is very difficult. Therefore, concrete strength in the test date may vary from 3.8 to $5.4 \mathrm{MPa}$. The summaries of mix properties for concrete are shown in Table 1. All specimens were $200 \times 300 \mathrm{~mm}$ in cross section with the height of $1250 \mathrm{~mm}$. To study the effect of bar size on their seismic behavior, 4-DB12 was used as longitudinal reinforcement of two columns whilst 4-RB9 was used for the rest. The transverse reinforcement ratio of all specimens is very low around $0.1 \%$. The $90^{\circ}$ hook as shown in Figure 3 was used in all specimens. The longitudinal bar yield strength is about $470 \mathrm{MPa}$ and $354 \mathrm{MPa}$ for DB12 and RB9, respectively. For stirrup, the yield strength is $511 \mathrm{MPa}$. The properties of test specimens including reinforcement detailing are shown in Table 2.

2.2. Test Setup. The axial load was applied and maintained using a hydraulic jack, whilst the lateral load was applied using an actuator with $50 \mathrm{kN}$ loading capacity. The displacement controlled pattern as shown in Figure 4(b) was used in this test. The column will be pushed to the target drift twice to assure that the hysteretic loop is stable before increasing drift to subsequent cycle. The test setup is shown in Figure 4(a). The drift ratio of low strength concrete columns is made up of flexural, yield penetration, and shear components which can be measured using strain gauges and linear variable displacement transducer (LVDT). Twelve strain gauges were installed on the reinforcement to measure the longitudinal and transverse strains. The discussion on all sensors' measurement is currently under preparation and will be further reported in the future. The highlighted topic in this paper is the gravity load-carrying capacity of these NRCC columns. The axial collapse behavior of these columns is of most interest since this will significantly affect loss of life. Therefore, the test frame as shown in Figure 4(a) was specially designed to be able to maintain the axial load during the test. The test was not terminated when the lateral resistance

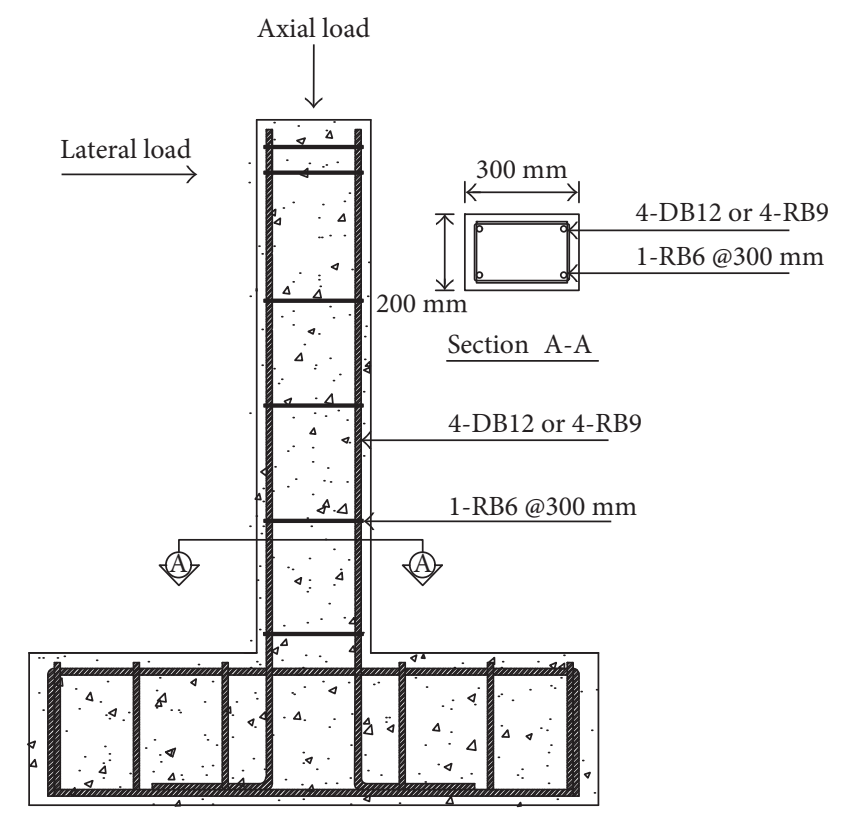

Figure 3: Reinforcement details of column specimens.

dropped by $20 \%$ of the maximum lateral force as typical cyclic load test. The test was performed beyond this point and terminated only when the axial load cannot be maintained. In this test, axial displacement at the tip of the columns was measured using LVDT in order that axial shortening behavior before gravity load collapse could be monitored.

\section{Crack Pattern Results}

3.1. The Lateral Drifts at $1.5 \%$. The crack patterns at $1.5 \%$ drift of all column specimens are shown in Figure 5 . The pattern of crack in all columns was very similar and found to be initiated by flexural crack. The cracks propagated and changed to shear crack pattern near the centerline of the columns. It was evidently found that the cracks were widely spread up to $500 \mathrm{~mm}$ from the base of the columns using DB12 longitudinal reinforcement (12L-0.2 and 12L-0.6). However, for columns using RB9 (9L-0.2 and 9L-0.6), the cracks were limited near the base area. Therefore, it can be concluded that the crack locations are related to the types of longitudinal reinforcement. The use of deformed bars as longitudinal reinforcement in NRCC may cause widespread of crack along the column height. In contrast, the cracks seem to be limited in the plastic hinge location when round bars were used. The axial load levels also have significant influence on the crack pattern. From Figure 5, the cover spalling was observed in the high axial load columns (9L-0.6 and 12L-0.6). The concrete cover spalling in the first few cycles may cause the longitudinal bar buckle leading to column collapse at a very low drift. 
TABle 2: Properties of column specimens.

\begin{tabular}{|c|c|c|c|c|c|c|c|c|}
\hline Group & $\begin{array}{c}\text { Specimen } \\
\text { designation }\end{array}$ & $\begin{array}{c}\text { Ultimate } \\
\text { strength } \\
\text { concrete }(\mathrm{MPa})\end{array}$ & $\begin{array}{c}\text { Axial } \\
\text { load }(\mathrm{kN})\end{array}$ & $\begin{array}{l}\text { Longitudinal } \\
\text { reinforcing } \\
\text { ratio }(\%)\end{array}$ & Main rebar & $\begin{array}{c}\text { Dimensions } \\
(\mathrm{mm})\end{array}$ & $\begin{array}{l}\text { Transverse } \\
\text { reinforcement } \\
\text { ratio (\%) }\end{array}$ & Ties (@mm) \\
\hline \multirow{2}{*}{ Group 1} & $12 \mathrm{~L}-0.2$ & 4.8 & 58.86 & 0.75 & 4-DB12 & $200 \times 300$ & 0.07 & RB6@300 \\
\hline & $12 \mathrm{~L}-0.6$ & 3.8 & 176.58 & 0.75 & 4-DB12 & $200 \times 300$ & 0.07 & RB6@300 \\
\hline \multirow{2}{*}{ Group 2} & $9 \mathrm{~L}-0.2$ & 5.4 & 58.86 & 0.31 & 4-RB9 & $200 \times 300$ & 0.07 & RB6@300 \\
\hline & $9 \mathrm{~L}-0.6$ & 5.0 & 176.58 & 0.31 & 4-RB9 & $200 \times 300$ & 0.07 & RB6@300 \\
\hline
\end{tabular}

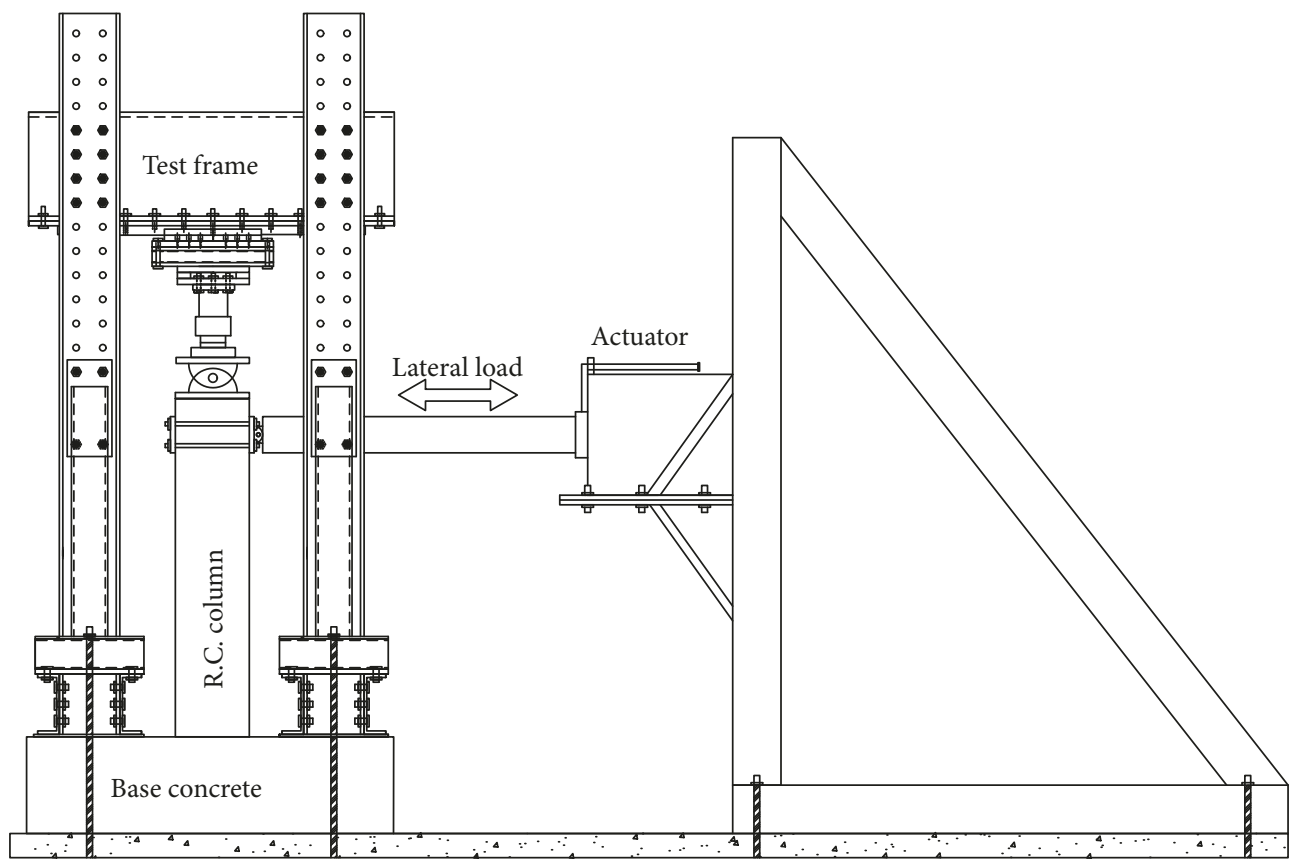

(a)

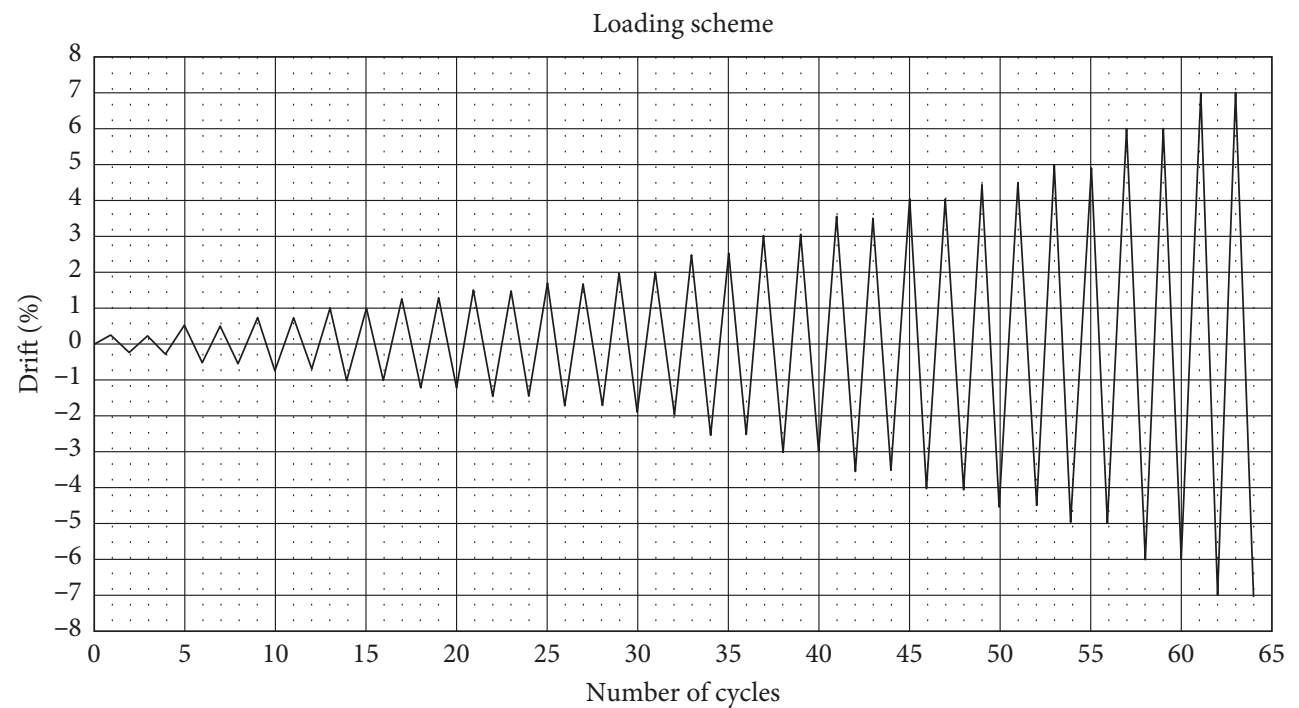

(b)

FIgUre 4: (a) Test setup. (b) Cyclic loading history.

3.2. The Lateral Drifts at Collapse. After $1.5 \% \mathrm{drift}$, the test has been carried on, and the lateral drift of all columns increased to the next target drifts until the collapse stage. In this study, the collapse is defined as the drift at which the column could not sustain its gravity load. When the drift increased, the existing cracks were propagated to the center, and the cracks have increased size and length. Figure 6 shows the crack pattern at collapse and failure mode of all the tested columns. 


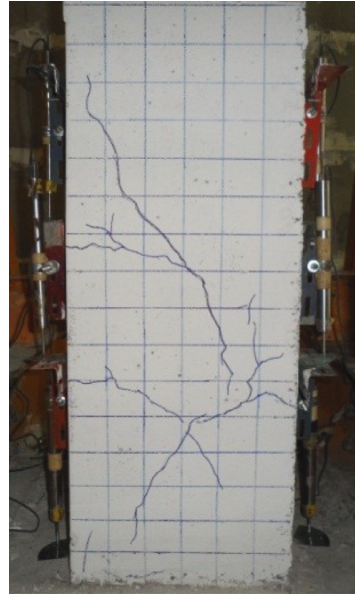

(a)

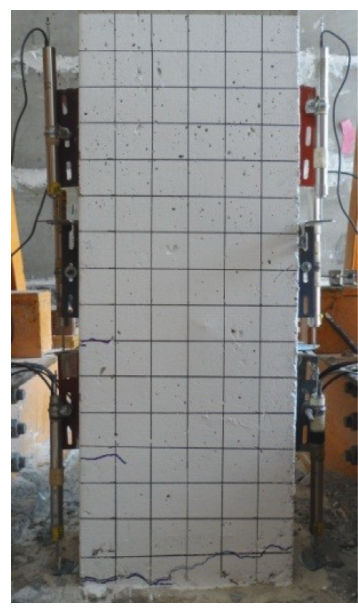

(c)

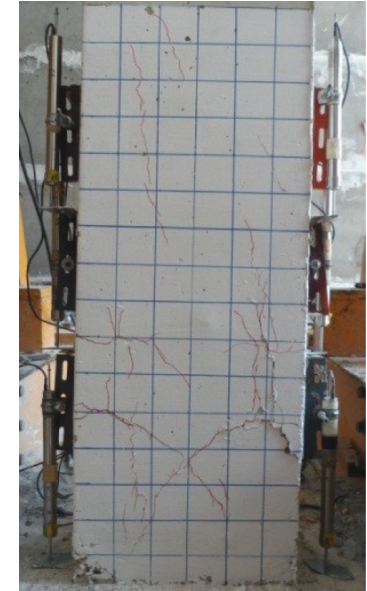

(b)

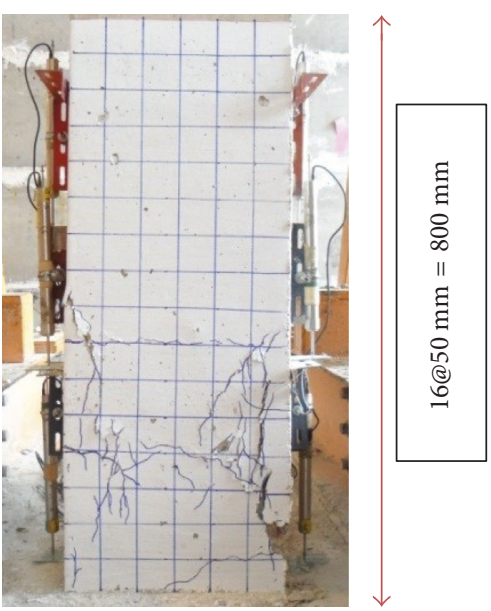

(d)

Figure 5: The levels of damage at the rate of lateral movement (at 1.5\% drift). (a) 12L-0.2, (b) 12L-0.6, (c) 9L-0.2, and (d) 9L-0.6.

The failure patterns of the four column specimens were significantly different. However, there are two main patterns. The first pattern is concrete splitting along the column height as observed in the failure mode of the columns $12 \mathrm{~L}$ 0.2 and 12L-0.6, as illustrated in Figures 6(a) and 6(b). In these columns, the inclined shear cracks were initiated due to the larger applied maximum shear force (compared to those in 9L-0.2 and 9L-0.6) associated with larger amount of longitudinal bars. After shear cracking, the longitudinal bars buckling was observed. Eventually, the column lost its integrity and collapse under gravity load at the drift of $4 \%$ and $1.75 \%$ for column $12 \mathrm{~L}-0.2$ and $12 \mathrm{~L}-0.6$, respectively. The second pattern is concrete crushing within the plastic hinge region as observed in the failure mode of the column 9L-0.2 and 9L-0.6, as illustrated in Figures 6(c) and 6(d). In these columns, the flexural cracks were initiated near the column base. The cracks did not propagate through the height of the column but were confined to the plastic hinge area. Eventually, concrete splitting and bar buckling were limited only in the plastic hinge area. The gravity load collapse at the drift of $3.5 \%$ and $1.75 \%$ for column $9 \mathrm{~L}-0.2$ and $9 \mathrm{~L}-0.6$, respectively. It was found that the crack pattern and location mainly depend on the type of longitudinal reinforcement.
When DB12 bars were used as a longitudinal reinforcement, the crack size was very large and dissipated all over the columns. In contrast, when the round bars were used, the cracks were limited to only in the plastic hinge location. Although the crack patterns of the columns using the same bar type are similar, the maximum drifts at failure of the columns are significantly different. The high axial load columns (9L-0.6 and 12L-0.6) collapsed under gravity load only at a drift of $1.75 \%$. For columns subjected to lower axial load, the drift at collapse of the columns using round bars (9L-0.2) was $4 \%$ but $3.5 \%$ drift for the column using deformed bars (12L-0.2). When the deformed bars were used, the column could tolerate lateral displacement slightly less than that using round bar providing that the axial load level was low. It is evident that the drift at axial load collapse of NRCC columns is significantly dependent on axial load level but slightly dependent on type of longitudinal reinforcement. The type of longitudinal reinforcements plays more important role on drift level only when the axial load level is low. The use of round bars in NRCC is recommended since it could lead to columns collapse under gravity load at larger drift compared to those using deformed bar. 


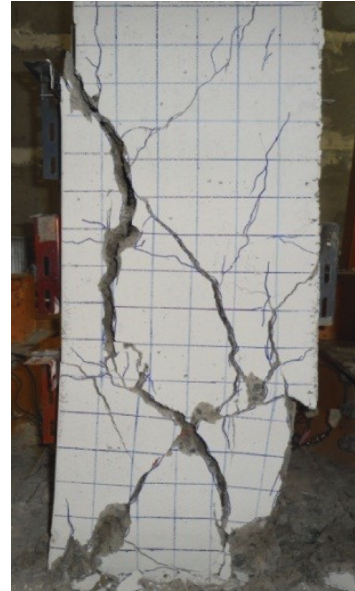

(a)

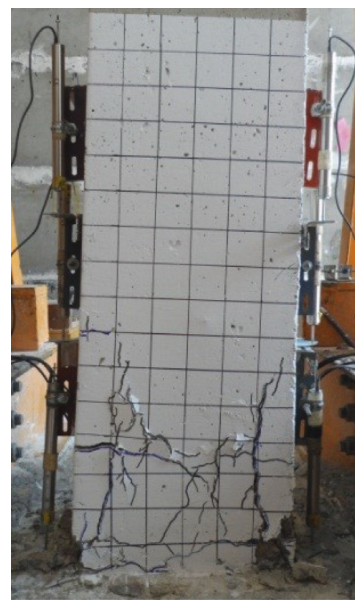

(c)

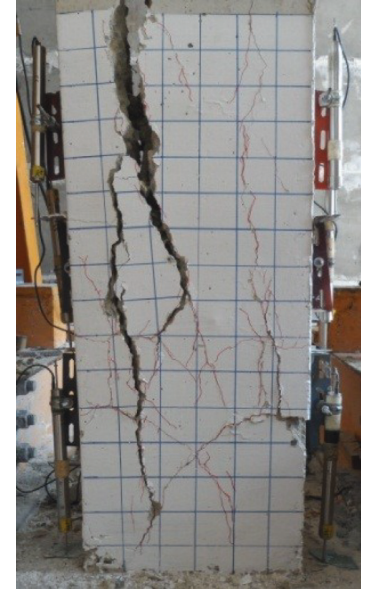

(b)

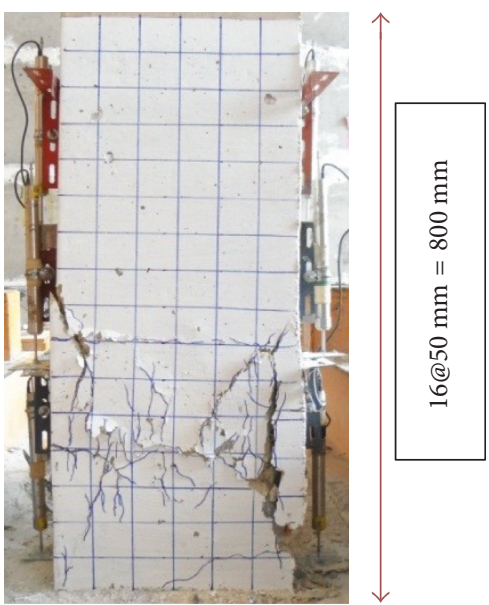

(d)

Figure 6: Failure pattern of column specimens. (a) 12L-0.2 (3.5\% drift); (b) 12L-0.6 (1.75\% drift); (c) 9L-0.2 (4.0\% drift); (d) 9L-0.6 (1.75\% drift).

\section{Lateral Load-Drift Ratio Responses}

Figure 7 shows the relationship between lateral load and drift ratio (including displacement) of all the test specimens. The lateral force was measured using load cell attached to the actuator arm. The displacement of the columns was measured using LVDT to monitor movement at the column tip. The measured displacement was used to calculate drift ratio by dividing column shear span $(1.25 \mathrm{~m})$. The lateral load was then plotted against drift ratio as shown in Figure 7.

During the low drift cycle (less than $0.5 \%$ ), the hysteresis loop of all columns was very stable, and the linear relationship between force and displacement was observed in the ascending curve in the first and second cycle. This can be implied that the column behavior under cyclic loading in a very low drift is in the elastic range. When the drift cycle increases, the second hysteretic loop shows peak loop strength degradation. Furthermore, it was observed that when the deformed bars were used (12L-0.6 and 12L-0.2), there was a significant lateral peak strength drop in the second cycle. Much less second cycle strength drop was observed in the columns using round bars (9L-0.2 and 9L-0.6). The effect of axial load level on cyclic behavior of NRCC is also very important. The columns 12L-0.2 and 9L-0.2 that were subjected to low axial load could tolerate larger number of cycles compared to those subjected to high axial load (12L-0.6 and 9L-0.6). Therefore, the energy dissipation of these low axial load columns was higher than the counterparts as shown in Figure 7. The use of different bar types also influenced the shape of hysteretic loop. The loop was narrow when the deformed bars were used compared to those using round bars. Consequently, the energy dissipation of the columns using deformed bars was lower than those using round bars providing that the axial load ratios were equal.

\section{The Envelope Curves of All Specimens}

To compare the overall force and drift behavior under cyclic loading of all specimens, the envelop curves of lateral loaddrift relationship of all specimens were plotted as shown in Figure 8. All specimens showed the elastic behavior under low level of lateral force. In term of lateral resistance, the maximum resistance was obtained when $12 \mathrm{~mm}$ deformed bars were used (12L-0.2) under low axial load level. However, with the same deformed bars, higher axial load level (12L-0.6) 


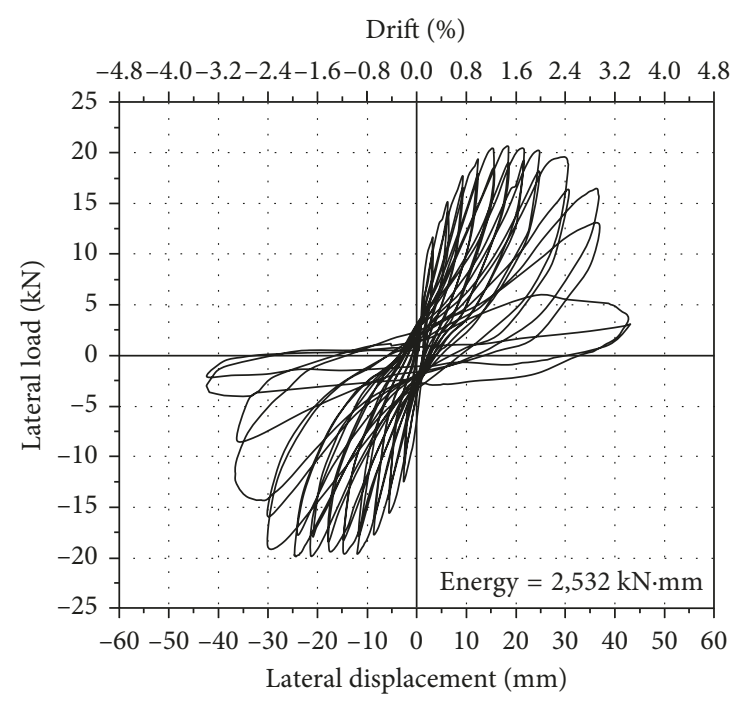

(a)

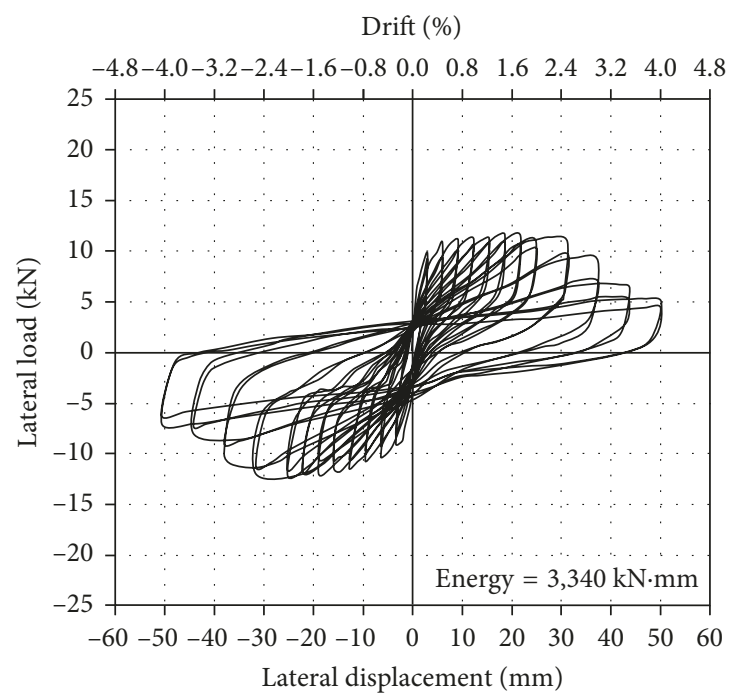

(c)

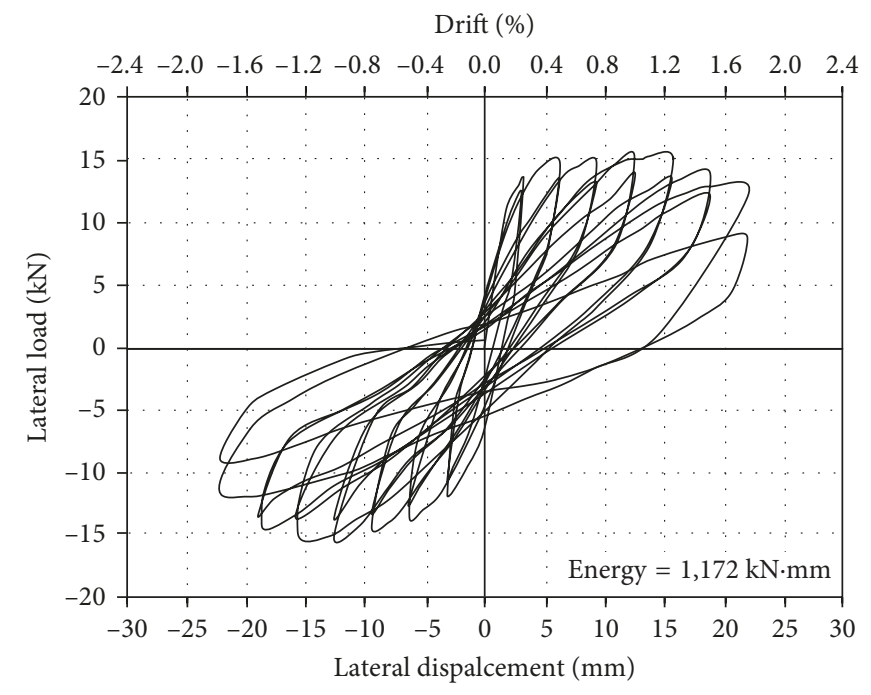

(b)

Drift (\%)

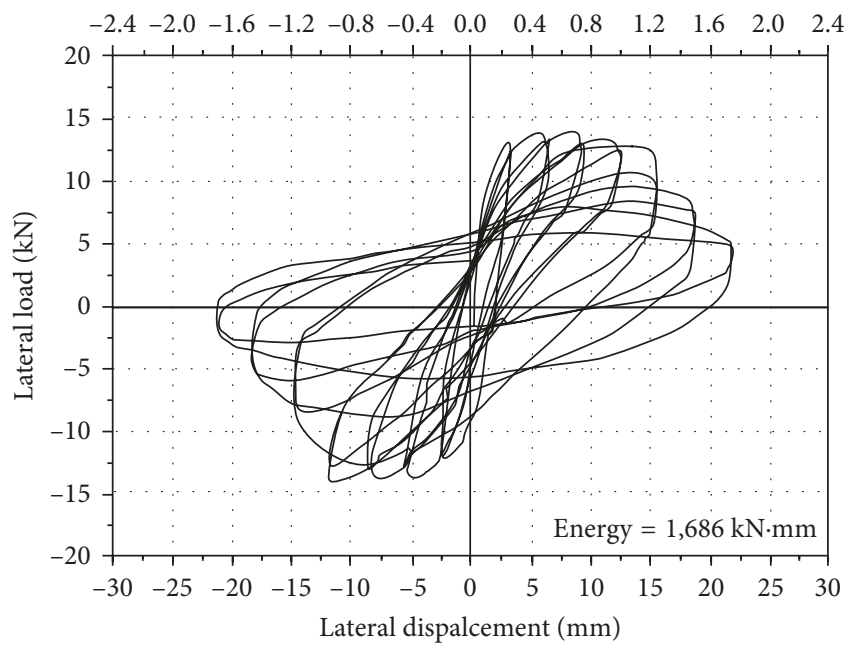

(d)

FIGURE 7: Lateral load-drift ratio responses. (a) 12L-0.2; (b) 12L-0.6; (c) 9L-0.2; (d) 9L-0.6.

decreased the column lateral resistance. This is due to the compression failure of low strength concrete associated with concrete crushing before longitudinal reinforcement developing their full tensile strength. When concrete crushing in the column subjected to high axial load level, the axial collapse occurred at a very low drift of $1.75 \%$. The use of round bars in the low axial load column (9L-0.2) significantly influenced on lateral load resistance capacity. The lateral resistance of the low axial load columns was significantly dependent on and proportional to amount of longitudinal reinforcement. The lateral resistance of columns under low axial load level was evidently controlled by tensile resistance of steel since tension failure mode is controlled overall behavior of such columns. However, the use of round bars seems to slightly benefit the column drift capacity. For example, the column 9L-0.2 has a larger drift at collapse than the column 12L-0.2. For columns under high axial load ratio, the envelop curves of both columns (12L-0.6 and 9L-0.2) including drift capacity at collapse were not significantly different as shown in Figure 8 . This is due to the fact that the overall behavior is controlled by compression failure as previously discussed.

The column test results are summarized in Table 3 . In the case of axial load level at 6 ton, the maximum lateral load of specimens $12 \mathrm{~L}-0.2$ was $23.25 \mathrm{kN}$. This lateral load was significantly higher than that of specimen $9 \mathrm{~L}-0.2(13.8 \mathrm{kN})$. On the other hand, the drift at failure of specimens $12 \mathrm{~L}-0.2$ is $3.5 \%$. This lateral load was lower than that of specimen 9L-0.2 (4\% drift). In this case, the maximum lateral resistant of the columns with longitudinal reinforcement ratio 0.75 was higher than that of 0.31 . In contrast, the drift at failure of the column with longitudinal reinforcement ratio 0.75 was lower than that of 0.31 .

When the axial load level increased to 18 ton, the maximum lateral load and drift at failure for both specimens 12L-0.6 and 9L-0.6 were rather similar, as shown in Table 3. The test results indicated that the axial load ratio affects maximum lateral load and drift capacity of all columns. 


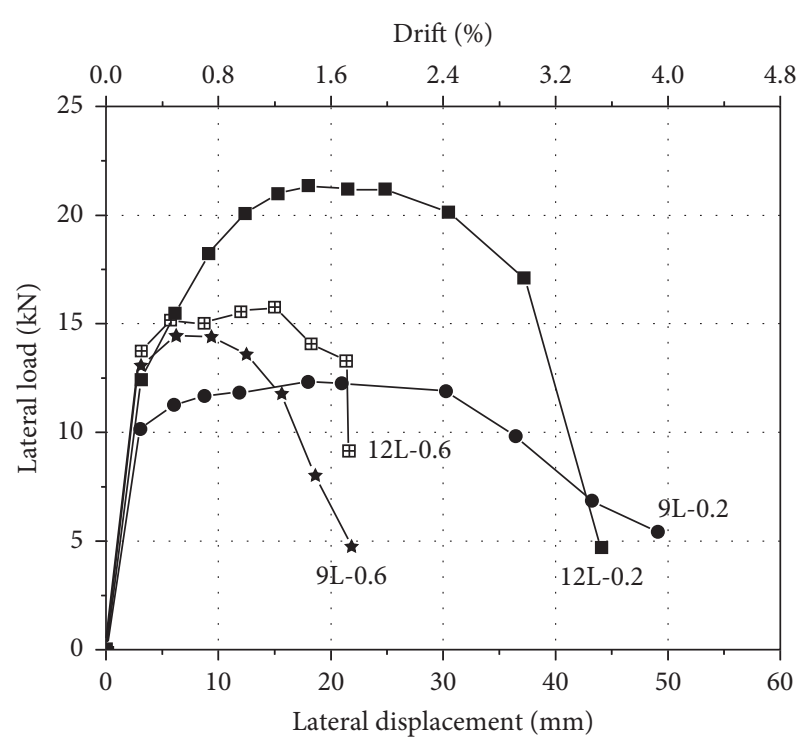

FIgURE 8: The envelope curve of all specimens.

\section{Axial Displacement and Drift Ratio Relationship}

Figure 9 shows the relationship between axial deformation and lateral displacement of the NRCC columns under cyclic loading. During the cyclic load test, the axial load level was kept constant throughout the test, and the axial displacement was carefully monitored using a displacement transducer mounted at the top of the columns. From Figure 9, during the first few cycles, there was no significant axial shorting of all test columns. When the lateral drift was increased and the column cracking and concrete cover spalling were evidently observed, the axial shortening had started to increase. It was observed that before the peak resistance (as marked by (1) in Figure 9), there was almost no axial shortening. However, after peak load or postpeak regions, the axial shortening had initiated and sharply increased after point (2) as shown in Figure 9. When the second cyclic loop was applied, the axial shortening has continuously increased, and hence, this point was deemed the gravity load collapse. The drifts at this stage of all test columns were recorded and are summarized in Table 3. This drift at axial load collapse is the most realistic collapse point that can be used to justify the maximum drift of NRCC columns.

The influence of various parameters on gravity load collapse mechanism of NRCC columns has also been studied. For the column 12L-0.2, the largest amount of longitudinal reinforcement and lowest axial force were used. It was found that that axial shortening occurred at a very high drift (almost $3 \%)$. However, once the axial shortening has been initiated, gravity load collapse occurred soon after this point $(3.5 \%$ drift). The initiation of axial shortening at high drift compared to other columns because the longitudinal reinforcements have a significant contribution to carrying the axial load (at low level). However, when the concrete cover was spalling at high drift, the bars were not effectively confined by concrete cover. Eventually, load-carrying capacity of the bars has been
TABLE 3: Summaries of the column specimens test results.

\begin{tabular}{lcccc}
\hline Specimen & 12L-0.2 & 12L-0.6 & 9L-0.2 & 9L-0.6 \\
\hline $\begin{array}{l}\text { Ultimate strength concrete } \\
\text { (MPa) }\end{array}$ & 4.80 & 3.80 & 4.00 & 5.40 \\
$\begin{array}{l}\text { Longitudinal reinforcing ratio } \\
\text { Maximum lateral load (kN) }\end{array}$ & 0.75 & 0.75 & 0.31 & 0.31 \\
$\begin{array}{l}\text { Drift at maximum load (\%) } \\
\text { Lateral load at 80\% of peak }\end{array}$ & 1.50 & 16.32 & 13.80 & 15.65 \\
load (kN) & 18.60 & 13.06 & 11.40 & 0.76 \\
$\begin{array}{l}\text { Drift at 80\% of peak load (\%) } \\
\text { Lateral load at axial }\end{array}$ & 3.00 & 1.76 & 3.08 & 1.26 \\
failure (kN) & 0.89 & 1.20 & 0.67 & 0.85 \\
Drift at axial failure (\%2) & 3.49 & 1.76 & 4.06 & 1.79 \\
\hline
\end{tabular}

lost due to compression buckling followed by sharply axial shortening, leading to gravity load collapse of the column.

For the column 12L-0.6, the axial load level was increased and consequently, higher axial stress has imposed on both concrete and longitudinal bars. The axial shortening has initiated soon after the peak lateral load. The sharp increase in axial displacement occurred when the number of cycle increased. Concrete crushing following by bars buckle at a very low drift caused the rapid column shortening following gravity load collapse of the column. When longitudinal reinforcement ratio was reduced approximately $50 \%$ (columns 9L-0.2 and 9L-0.6), axial load-carrying capacity contributed by longitudinal reinforcement was therefore reduced approximately $50 \%$. In this case, the more proportion of axial load will be transferred to concrete compared to the columns using $4 \mathrm{db}$ (12 bars). Hence, the shortening behavior was likely to be controlled by behavior of concrete under compression. The axial shortening has initiated soon after the peak lateral resistance and continuously increased until gravity load collapse was imminent. It was also found that when the level of axial load was high such as in the column 9L-0.6, the axial deformation increased rapidly when the number of cycle and drift increased.

\section{Theoretical Model for Column Collapse}

In this section, the numerical framework is proposed to predict the behavior of low strength concrete columns by plastic hinge concept such as the well-known Paulay model in 1923. The model could provide a conservative estimate when used for evaluating seismic resistance of reinforced concrete structures [25]. The model was used to predict the maximum lateral load and ultimate drift ratio, as shown in Table 4. Comparison has been made between prediction results and test result for all specimens.

Ductility of reinforced concrete column $\left(\mu_{\Delta}\right)$ can be calculated from the Paulay model in 1923 [26]:

$$
\mu_{\Delta}=\frac{\Delta_{\mathrm{m}}}{\Delta_{\mathrm{y}}},
$$

where $\Delta_{\mathrm{m}}=\Delta_{\mathrm{y}}+\Delta_{\mathrm{p}}, \Delta_{\mathrm{m}}$ is the maximum displacement $(\mathrm{mm}), \Delta_{\mathrm{y}}$ is the yield displacement $(\mathrm{mm})$, and $\Delta_{\mathrm{p}}$ is the plastic displacement $(\mathrm{mm})$.

The yield displacement $\left(\Delta_{\mathrm{y}}\right)$ of cantilever may be estimated as follows: 
Drift (\%)

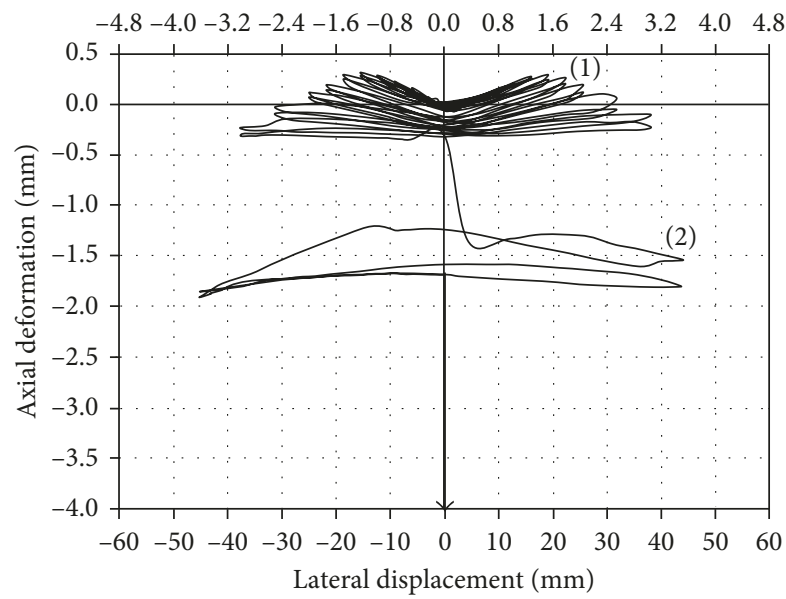

(1) Peak shear strength

(2) Gravity load collapse

(a)

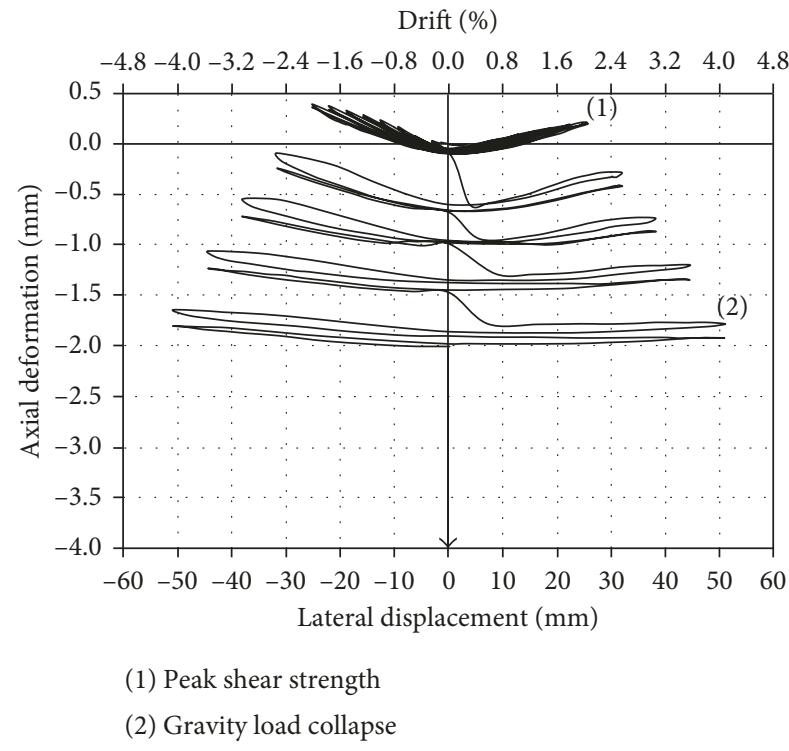

(c)

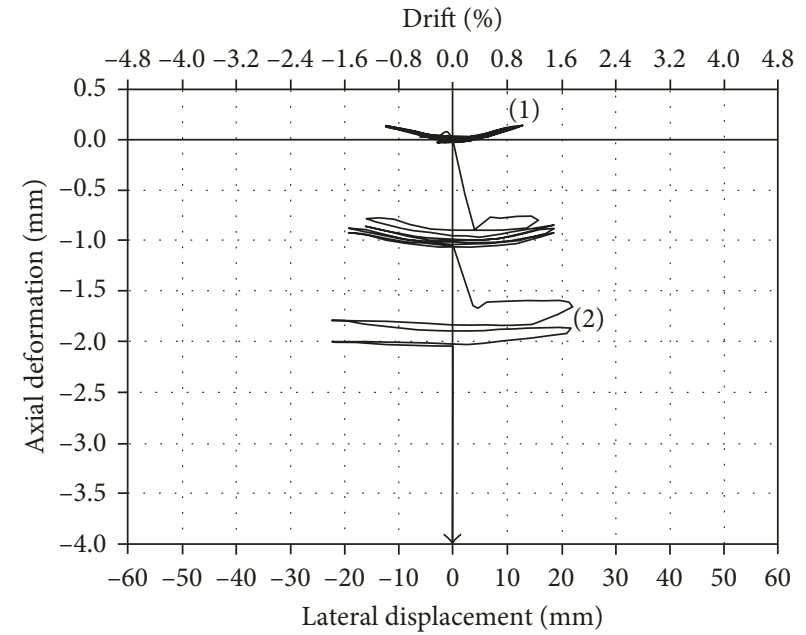

(1) Peak shear strength

(2) Gravity load collapse

(b)

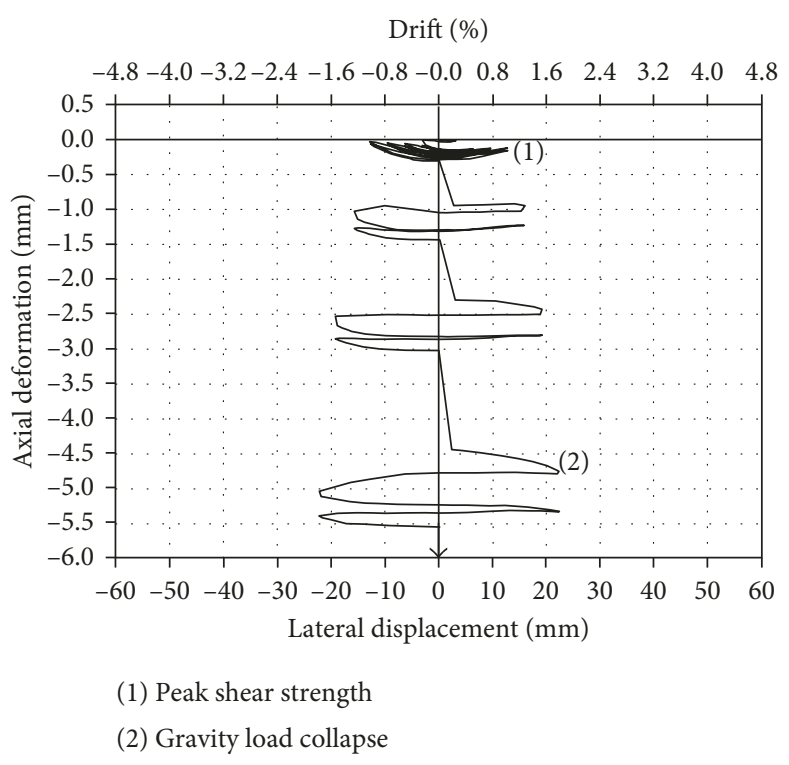

(d)

Figure 9: Axial displacement-drift ratio response. (a) 12L-0.2; (b) 12L-0.6; (c) 9L-0.2; (d) 9L-0.6.

$$
\Delta_{\mathrm{y}}=\frac{\phi_{\mathrm{y}} l^{2}}{3}
$$

where $\phi_{\mathrm{y}}$ is the yield curvature $(\mathrm{rad} / \mathrm{mm})$ and $l$ is the length of column ( $\mathrm{mm})$.

From Figure 10, the yield curvature $\left(\phi_{\mathrm{y}}\right)$ is given by $\phi_{\mathrm{y}}=$ $M_{i} / M_{i}^{\prime} \phi_{i}^{\prime}$ an acceptable approximation for beam sections to calculate the steel and concrete extreme fiber strain, and hence curvature $\phi_{y}^{\prime}$, based on conventional elastic section analysis at a moment of $M_{i}^{\prime}=0.75 M_{i}$ thus providing an equivalent yield curvature of $\phi_{\mathrm{y}}=1.33 \phi_{y}^{\prime}$, when

$$
\phi_{y}^{\prime}=\frac{\varepsilon_{\mathrm{y}}}{(d-c)}
$$

where $\varepsilon_{\mathrm{y}}$ is the yield strain of longitudinal reinforcements, $c$ is the distance between the top of the compressive section and the neutral axis NA ( $\mathrm{mm})$, and $d$ is the effective depth ( $\mathrm{mm})$.

From Figure 11, assuming that the plastic rotation to be concentrated at the mid-height of the plastic hinge, thus, the plastic displacement at cantilever tip is

$$
\Delta_{\mathrm{p}}=\theta_{\mathrm{p}}\left(l-\frac{l_{\mathrm{p}}}{2}\right)=\left(\phi_{\mathrm{m}}-\phi_{\mathrm{y}}\right) l_{\mathrm{p}}\left(l-\frac{l_{\mathrm{p}}}{2}\right),
$$

where $\phi_{\mathrm{m}}$ is the maximum curvature $(\mathrm{rad} / \mathrm{mm}), \phi_{\mathrm{p}}$ is the plastic hinge curvature $(\mathrm{rad} / \mathrm{mm})$, and $l_{\mathrm{p}}$ is plastic hinge length of the column $(\mathrm{mm})$. The maximum curvature $\left(\phi_{\mathrm{m}}\right)$ is given by 
TABLE 4: Maximum lateral strength and ultimate drift ratio.

\begin{tabular}{|c|c|c|c|c|c|c|}
\hline \multirow[b]{2}{*}{ Group } & \multirow[b]{2}{*}{$\begin{array}{c}\text { Specimen } \\
\text { designation }\end{array}$} & \multirow{2}{*}{$\begin{array}{l}\text { Ultimate strength } \\
\text { concrete }(\mathrm{MPa})\end{array}$} & \multicolumn{2}{|c|}{ Experiment } & \multicolumn{2}{|c|}{ Theoretical prediction } \\
\hline & & & $\begin{array}{c}\text { Maximum lateral } \\
\text { strength }(\mathrm{kN})\end{array}$ & $\begin{array}{l}\text { Ultimate drift } \\
\text { ratio }(\%)\end{array}$ & $\begin{array}{c}\text { Maximum lateral } \\
\text { strength }(\mathrm{kN})\end{array}$ & $\begin{array}{l}\text { Ultimate drift } \\
\text { ratio }(\%)\end{array}$ \\
\hline \multirow{2}{*}{ Group 1} & $12 \mathrm{~L}-0.2$ & 4.8 & 23.25 & 3.496 & 21.62 & 1.033 \\
\hline & $12 \mathrm{~L}-0.6$ & 3.8 & 16.32 & 1.760 & 19.76 & 0.411 \\
\hline \multirow{2}{*}{ Group 2} & $9 \mathrm{~L}-0.2$ & 5.4 & 13.80 & 4.056 & 12.59 & 1.400 \\
\hline & 9L-0.6 & 5.0 & 15.65 & 1.785 & 14.32 & 0.560 \\
\hline
\end{tabular}

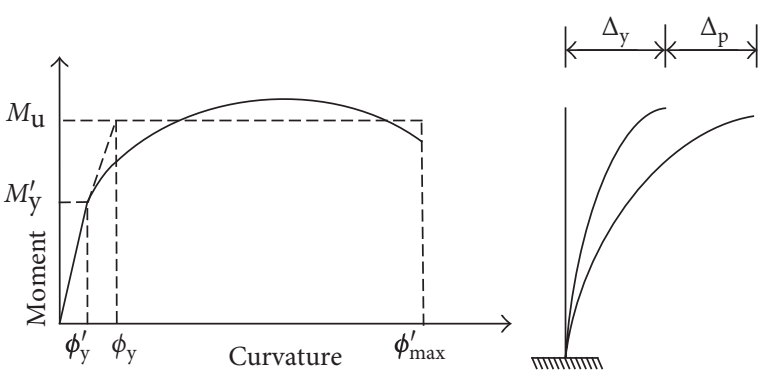

FIGURE 10: Lateral displacement-moment curvature.

$$
\phi_{\mathrm{m}}=\frac{\varepsilon_{\mathrm{m}}}{C_{u}}
$$

where $C_{u}$ is the distance between the top of the compressive section and the neutral axis NA at the maximum curvature $(\mathrm{mm})$.

The plastic hinge length of column $\left(l_{\mathrm{p}}\right)$ can be estimated as

$$
l_{\mathrm{p}}=0.5 \mathrm{~h}
$$

where $h$ is the section depth $(\mathrm{mm})$.

\section{Numerical Simulation}

The prediction of the maximum lateral strength and ultimate drift of all test columns are shown in Table 4 along with the results from the experiment. The prediction of maximum lateral strength was calculated by simply applying the concept of plane stress remaining plain after bending. The material models used in this calculation (concrete and longitudinal reinforcement) were calibrated against material testing results. It was found that the predictions provide slightly lower values compared to test result except those in column 12L-0.6. For column 12L-0.6, the predicted lateral strength $(19.76 \mathrm{kN})$ is higher than the test result $(16.32 \mathrm{kN})$. This might be a result of the concrete cover splitting along the column height at the early stage (as shown in Figure 5). It partially prevented the longitudinal bars to be able to fully develop their yield stresses.

To calculate lateral drift, the well-known Paulay model as explained in previous section was adopted. The plastic hinge length used in this study was equal to $0.5 \mathrm{~h}$, and the limiting strain at ultimate drift is 0.003 . From Table 4 , it was evidently found that the model was overly conservative in predicting the lateral drift at gravity load collapse. The model under predicted the lateral drift varying from $65 \%$ to $77 \%$ compared to the test results. It was found that the use of limiting plastic hinge length of only $0.5 \mathrm{~h}$ or $17.5 \mathrm{~cm}$ from the base might not be suitable for low strength columns. Since the damage and cracking were not limited to only that region, the crack locations were significantly dependent on the type of longitudinal reinforcement, axial load level, and also strength of concrete. In addition, the use of limiting concrete crushing strain of 0.003 may be too low for such low strength concrete. The model to more precisely predict the lateral drift at gravity load collapse is still under development. The developing of constitutive model of such low strength concrete will be further developed and calibrated against the compressive load test of the low strength cylinder. The recommendation of plastic hinge length model and new calculation approach will be presented in future.

\section{Conclusions}

This paper presents an experimental and numerical study on the cyclic performance of nonengineered reinforced concrete columns with distinct longitudinal bars and increased axial ratio. Based on the study, the test result revealed the following conclusions:

(1) From the crack pattern and damage observation, it can be concluded that the longitudinal reinforcement ratio was a significant factor on the crack pattern of the column under cyclic loading. Vertical crack along longitudinal reinforcing with deformed bars was found. However, the crack pattern of longitudinal reinforcing round is limited near the base area.

(2) From the hysteretic loop pattern observation, it can be concluded that the longitudinal reinforcement bars was a significant factor on the shape of hysteretic loop. The use of different bars types also influences energy dissipation. The energy dissipation is low when the deformed bars are used when compared to those using round bars.

(3) From the envelop curves of lateral load-drift relationship observation, it can be concluded that the lateral resistance of the low axial load columns was significantly dependent on and proportional to amount of longitudinal reinforcement. The lateral resistance of columns subject to low axial load level was evidently controlled by tensile resistance of steel since tension failure mode controlled the overall 


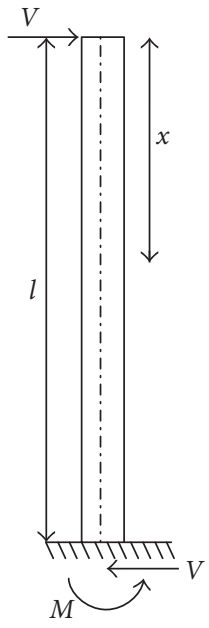

(a)

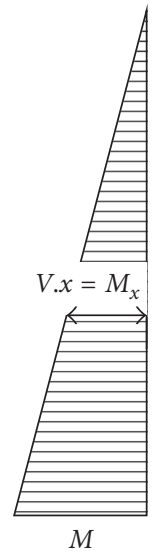

(b)

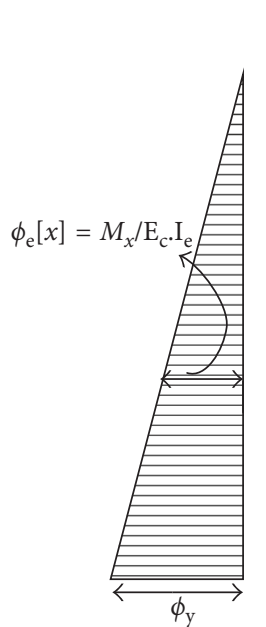

(c)

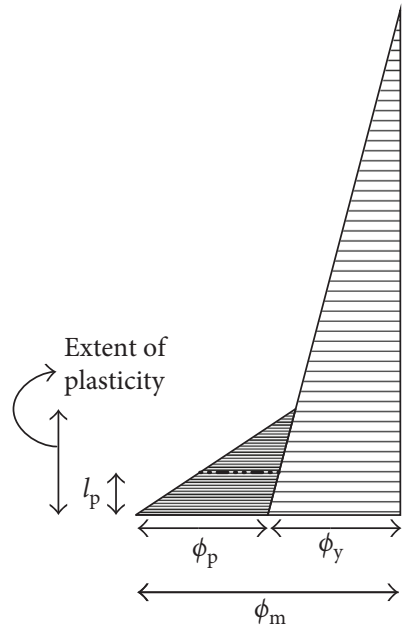

(d)

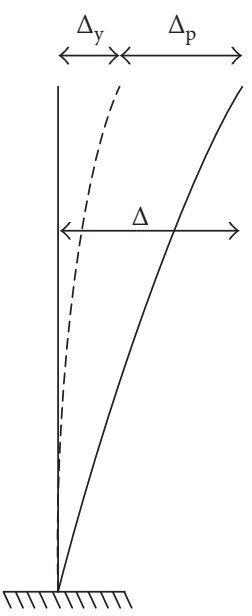

(e)

FIGURE 11: Moment curvature and deflection relationships for prismatic reinforced concrete. (a) Free body diagram of column; (b) moment; (c) yield curvatures; (d) curvature at maximum; (e) deflections.

behavior of such columns. The test results indicated that the axial load ratio affects maximum lateral load and drift capacity of all columns.
(4) From axial displacement and drift ratio relationship observation, it can be concluded that the initiation of axial shortening occurred at high drift compared to other columns. This is due to the fact the longitudinal reinforcements have a significant contribution in carrying the axial load (at low level). However, when the concrete cover was spalling at high drift, the bars were not effectively confined by concrete cover. Eventually, load-carrying capacity of the bars was lost due to compression buckling following by sharply axial shortening. Gravity load collapse of the column occurred as a consequence. In addition, the shortening behavior was likely to be controlled by behavior of concrete under compression. The axial shortening has initiated soon after the peak lateral resistance and continuously increased until gravity load collapse was imminent.

(5) The well-known Paulay model was used to predict the drift capacity of the NRCC columns in this study. It was found that the model was under predict lateral drift varying from $65 \%$ to $77 \%$ compared to the test results.

\section{Conflicts of Interest}

The authors declare that they have no conflicts of interest.

\section{Acknowledgments}

This research was supported by the Thailand Research Fund (TRF) year 2016-2017.

\section{References}

[1] P. Paultre and F. Legeron, "Confinement reinforcement design for reinforced concrete columns," Journal of Structural Engineering, vol. 134, no. 5, pp. 738-749, 2008.

[2] J. Cai and K. Suzuki, "An experimental study on reinforce concrete circular columns heavily confined by spiral reinforcement," in Proceedings of Eleventh World Conference on Earthquake Engineering, Acapulco, Mexico, June 1996.

[3] T.-S. Eom, S.-M. Kang, H.-G. Park, T.-W. Choi, and J.-M. Jin, "Cyclic loading test for reinforced concrete columns with continuous rectangular and polygonal hoops," Engineering Structures, vol. 67, pp. 39-49, 2014.

[4] X. Li, J. Wang, Y. Bao, and G. Chen, "Cyclic behavior of damaged reinforced concrete columns repaired with highperformance fiber-reinforced cementitious composite," Engineering Structures, vol. 136, pp. 26-35, 2017.

[5] W.-C. Liao, W. Perceka, and M. Wang, "Experimental study of cyclic behavior of high-strength reinforced concrete columns with different transverse reinforcement detailing configurations," Engineering Structures, vol. 153, pp. 290-301, 2017.

[6] P.-C. Chen, M.-L. Lin, and K.-C. Tsai, "Cyclic performance of full-scale RC columns retrofitted using external jacketing methods," in Proceedings of the 14th World Conference on Earthquake Engineering, Beijing, China, October 2008.

[7] A. R. Rahai, P. Sadeghian, and M. R. Ehsani, "Experimental behavior of concrete cylinders confined with CFRP 
composites," in Proceedings of the 14th World Conference on Earthquake Engineering, Beijing, China, October 2008.

[8] F. Colomb, H. Tobbi, E. Ferrier, and P. Hamelin, "Seismic retrofit of reinforced concrete short columns by CFRP materials," Composite Structures, vol. 82, no. 4, pp. 475-487, 2008.

[9] P. Faustino, P. Frade, and C. Chastre, "Lateral cyclic behaviour of RC columns confined with carbon fibres," Structures, vol. 5, pp. 196-206, 2016.

[10] M. Elchalakani and G. Ma, "Tests of glass fibre reinforced polymer rectangular concrete columns subjected to concentric and eccentric axial loading," Engineering Structures, vol. 151, pp. 93-104, 2017.

[11] R.-Y. Wu and C. P. Pantelides, "Rapid repair and replacement of earthquake-damaged concrete columns using plastic hinge relocation," Composite Structures, vol. 180, pp. 467-483, 2017.

[12] R. S. Aboutaha, M. D. Engelhardt, J. O. Jirsa, and M. E. Kreger, "Rehabilitation of shear critical concrete columns by use of rectangular steel jackets," ACI Structural Journal, vol. 96, no. 1, 1999.

[13] Y. Xiao and H. Wu, "Retrofit of reinforced concrete columns using partially stiffened steel jackets," Journal of Structural Engineering, vol. 129, no. 6, pp. 725-732, 2003.

[14] A. Ghobarah, A. Biddah, and M. Mahgoub, "Rehabilitation of reinforced concrete columns using corrugated steel jacketing," Journal of Earthquake Engineering, vol. 1, no. 4, pp. 651-673, 1997.

[15] A. He, J. Cai, Q.-J. Chen, X. Liu, H. Xue, and C. Yu, “Axial compressive behaviour of steel-jacket retrofitted RC columns with recycled aggregate concrete," Construction and Building Materials, vol. 141, pp. 501-516, 2017.

[16] G. T. Truong, J.-C. Kim, and K.-K. Choi, "Seismic performance of reinforced concrete columns retrofitted by various methods," Engineering Structures, vol. 134, pp. 217-235, 2017.

[17] K. Pletcher and J. Rafferty, "Sichuan earthquake of 2008 China," June 2017 , https://www.britannica.com/event/Sichuanearthquake-of-2008, event/Sichuan-earthquake-of-2008.

[18] Earthquake Engineering Research Institute, “The 12 January 2010 Haiti earthquake: emerging research needs and opportunities," in Proceedings of the Workshop on Earthquake Engineering and Design, Oakland, CA, USA, October 2010.

[19] N. Momoyo and M. Koichi, "Some considerations on strength and ductility of RC members with low strength concrete," in Proceedings of 14th World Conference on Earthquake Engineering, Beijing, China, October 2008.

[20] H. K. Miyamoto, A. S. Gilani, and A. Wada, "Reconnaissance report of the 2008 Sichuan earthquake, damage survey of buildings and retrofit option," in Proceedings of the 14th World Conference on Earthquake Engineering, Beijing, China, October 2008.

[21] Earthquake Engineering Research Institute, GEER Reconnaissance Team Field Report: The Wenchuan, Sichuan Province, China, Earthquake of May 12, p. 6, 2008.

[22] S. Eshghi and V. Zanjanizadeh, "Cyclic behavior of slender R/C columns with insufficient lap splice length," in Proceedings of 14th World Conference on Earthquake Engineering, Beijing, China, October 2008.

[23] C. Chintanapakdee, A. Ruangrassamee, and P. Lukkunaprasit, "Performance of masonry-infilled RC buildings in the M6.0 Mae Lao earthquake on May 5, 2014," in Proceedings of the Tenth Pacific Conference on Earthquake Engineering Building an Earthquake-Resilient Pacific, Sydney, Australia, May 2015.

[24] C. Boonmee, K. Rodsin, and K. Sriboonma, "Collapse behavior of low strength concrete under cyclic loading," in
Proceedings of International Conference on Materials Technology and Applications 2016 (ICMTA 2016), Singapore, October 2016.

[25] C. Boonmee and K. Rodsin, "Accuracy of the model based on plastic hinge concept in displacement estimation of nonductile reinforced concrete columns," in Proceedings of Annual Concrete Conference, West Lafayette, IN, USA, July 2014.

[26] T. Paulay and M. J. N. Priestley, Seismic Design of Reinforce Concrete and Masonry Buildings, A Wiley Interscience Publication, New York, NY, USA, 1992. 


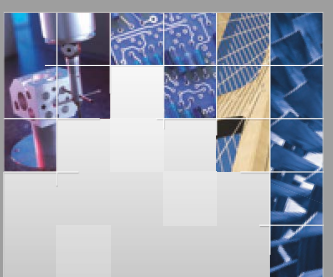

\section{Enfincering}
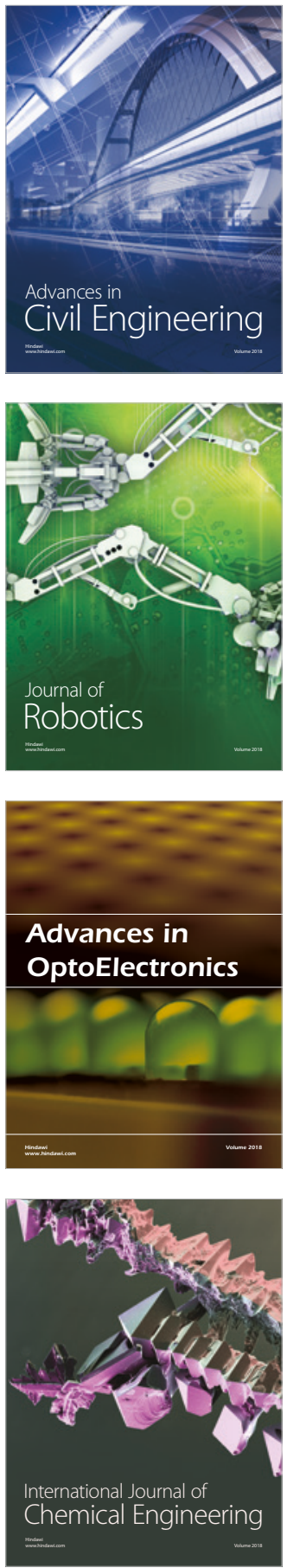

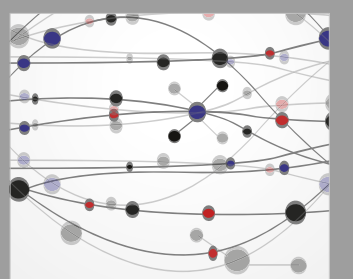

\section{Rotating \\ Machinery}

The Scientific World Journal

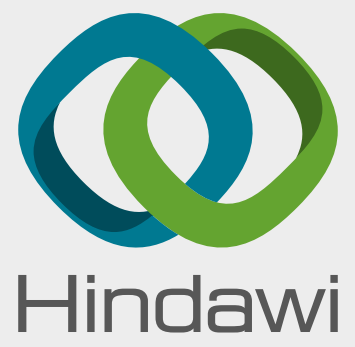

Submit your manuscripts at

www.hindawi.com
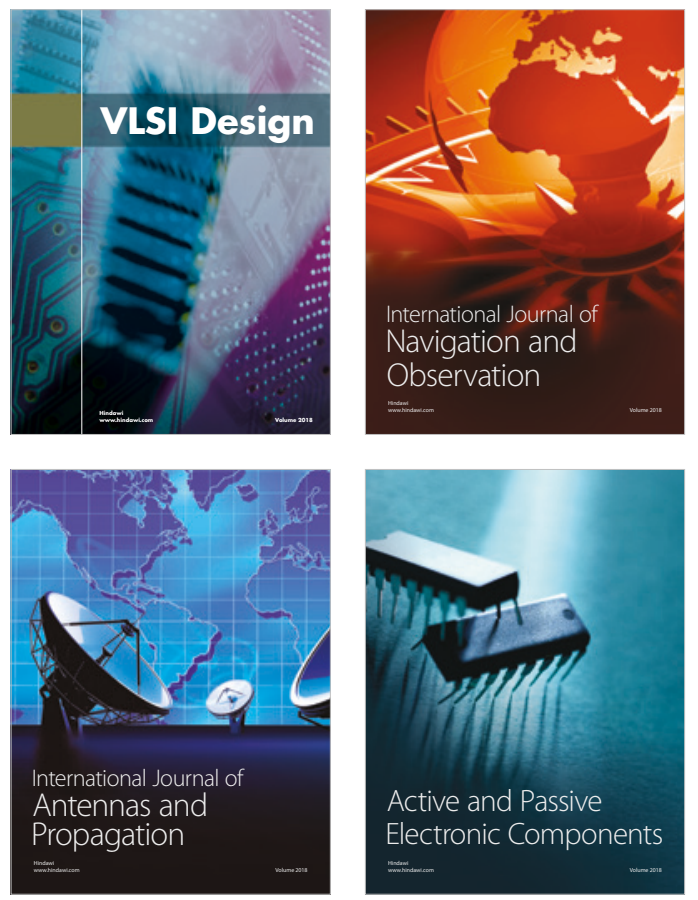
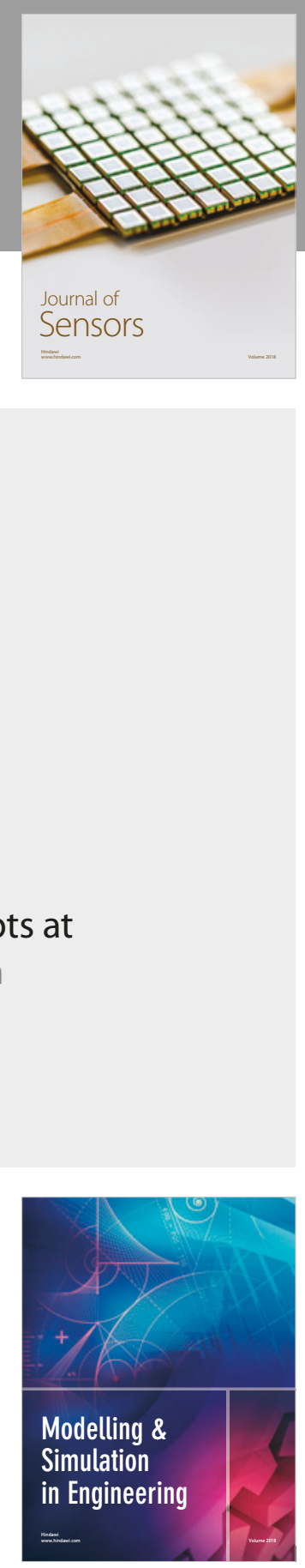

\section{Advances \\ Multimedia}
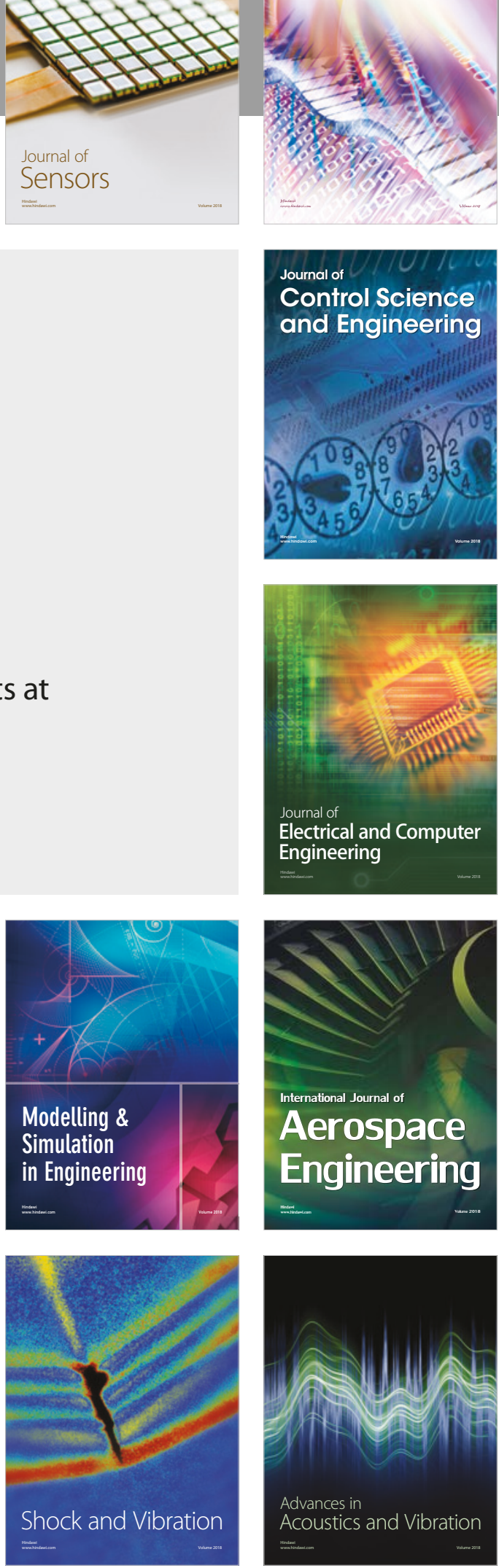